\title{
The Clinical Course of Severe Alpha-I-Antitrypsin Deficiency in Patients Identified by Screening
}

\section{Adriana-Maria Hiller (D) \\ Eeva Piitulainen \\ Hanan Tanash}

Department of Respiratory Medicine and Allergology, Lund University, Skåne

University Hospital, Malmö, Sweden
Correspondence: Adriana-Maria Hiller Department of Respiratory Medicine and Allergology, Lund University, Skåne University Hospital, Jan Waldenströms gata 24, plan 4, Malmö, S-205 02, Sweden Tel +4640331000

Email adriana-maria.hiller@med.lu.se
Background: Severe alpha-1-antitrypsin deficiency (AATD) is a genetic condition predisposing to chronic obstructive pulmonary disease (COPD) and liver disease. Its natural course is not well known. Our aim was to study the natural course of AATD by analyzing the clinical course in individuals with severe AATD identified by screening.

Materials and Methods: Of the 1585 individuals included in the Swedish AATD register, 377 (24\%) were identified by screening and included in this retrospective study. The followup time was from the date of inclusion in the register to the first lung transplantation, death or the termination of the study on June 1st, 2016. The risk factors for having a diagnosis of COPD were investigated through a proportional hazards model, adjusted for sex, diagnosis before the age of 14 years, smoking habits, occupational exposure to airway irritants and respiratory symptoms or diseases.

Results: At inclusion, $71 \%$ of the individuals were asymptomatic, ie, without any respiratory symptoms. Compared to the 156 (41\%) ever-smokers, the 221 (59\%) never-smokers had better lung function (mean $\mathrm{FEV}_{1} 98$ (SD 18) vs 85 (SD 28) \% predicted; p < 0.001), and fewer of them were symptomatic, ie, with respiratory symptoms, at inclusion ( $20 \% \mathrm{vs} 42 \%$; $\mathrm{p}<0.001)$. They also had a lower annual decline in $\mathrm{FEV}_{1}$ (mean 42 (95\% CI 36-47) vs 53 $(95 \%$ CI $\left.47-60) \mathrm{mL} \cdot \mathrm{yr}^{-1} ; \mathrm{p}=0.011\right)$ and better survival than the ever-smokers. The risk factors for having a diagnosis of COPD were the identification of severe AATD at an age of $\geq 14$ years and the presence of respiratory symptoms or diseases.

Conclusion: Never-smoking individuals with severe AATD identified by screening have better lung function, fewer symptoms, and better survival compared with the ever-smokers. Screening for AATD at an early age may improve the prognosis of AATD.

Keywords: alpha-1-antitrypsin, screening, clinical course, lung function, prognosis

\section{Introduction}

Alpha-1-antitrypsin (AAT) is a serine protease inhibitor, that protects lung tissue against the proteolytic destruction caused by neutrophil elastase (NE), one of the main serine proteases. ${ }^{1}$ In individuals with severe AAT deficiency (AATD), the plasma level of circulating AAT is only $10-20 \%$ of the normal level. ${ }^{2}$ The deficit of AAT in the circulation contributes to an imbalance between proteinases and antiproteinases, in favor of NE. ${ }^{1,2}$

In smoking individuals with severe AATD, Chronic Obstructive Pulmonary Disease (COPD) develops one to two decades earlier than in non-AATD smokers. ${ }^{3}$

AATD is often clinically underrecognized or misdiagnosed, and the diagnosis is delayed to the point when the pulmonary destruction is already established. ${ }^{1}$ AATdeficient individuals experience an accelerated rate of lung function decline and repeated exacerbations of COPD. ${ }^{4}$ 
In Sweden, the prevalence of severe AATD is approximately 1 of 1600 individuals, the investigation of the prevalence being based on a nationwide neonatal AAT screening program undertaken between 1972-1974, when 129 of the 200.000 newborns were found to have severe AATD. ${ }^{5}$ This unique nationwide neonatal screening of AATD had the purposes to study the prevalence of AATD in Sweden, the natural history of AATD and to prevent early exposure to air pollutants (primarily cigarette smoke). ${ }^{5}$ To our knowledge, this is the only cohort in the world with severe AATD that has been followed-up since birth on a regular basis. However, it still takes decades to study the complete natural course of AATD. The Swedish national register of individuals with severe AATD includes a large number of individuals identified by screening, and thus offers a unique possibility to study the natural course of AATD. ${ }^{6}$

Many of the previous studies on the natural course of AATD have reported that the condition leads to reduced life expectancy, compared with the general population. ${ }^{7-9}$ The fact that most of the patients included in previously published studies have been smokers and identified by the presence of symptoms or diseases, has influenced the results. However, our previously published analyses of data from the Swedish AATD register have shown a similar survival rate in never-smoking AAT-deficient individuals identified by screening compared with age and sex-matched controls. ${ }^{10,11}$ The health status and clinical course of AAT-deficient individuals identified through screening have only to a limited extent been investigated and the studies have included only a limited number of individuals. Also, the Swedish cohort includes only 129 individuals with severe AATD.

The aim of the present study was to investigate the health status, clinical course, and prognosis in individuals with severe alpha- 1 antitrypsin deficiency identified by screening.

\section{Methods}

This study was a retrospective, longitudinal, national, register-based study on individuals with severe AATD identified by means of screening. Data on the subjects were collected by cross-linkage using the Swedish system of personal identity numbers from the Swedish national patient register $(\mathrm{SNPR})^{12}$ and the national register of causes of death.

\section{Study Population and Data Collection}

The individuals with severe AATD included in this study were included in the Swedish AATD register, which has been described in detail elsewhere. ${ }^{6}$ Eligibility criteria for inclusion in the register are age $\geqslant 18$ years, written informed consent and a diagnosis of severe AATD (phenotypes PiZZ, PiZNull or PiNullNull), verified by isoelectric focusing, which is the standard method in Sweden for AAT phenotyping. In the Swedish AATD register, the reasons for the analysis of plasma proteins leading to the diagnosis of AAT deficiency are the following: the presence of any respiratory disease and/or symptoms, liver disease, other diseases, and screening. The clinical examination, laboratory analyses of blood samples and lung function tests are performed at the patients' local hospital every two years, and the results are reported by the attending physician to the AATD register via a questionnaire. Diagnoses of respiratory diseases, other diagnoses, symptoms, occupation, and smoking habits are also reported by the attending physician. Smoking status, based on the subjects' self-reports, was divided into two groups: neversmokers and ever-smokers. Ever-smokers included exsmokers and current smokers.

In the present study, "symptomatic individuals" were defined as the subjects who had any of the following at inclusion: respiratory symptoms or respiratory disease including asthma, COPD or emphysema reported by the attending physician or obtained from SNPR. The AATdeficient individuals without any respiratory symptoms or disease at inclusion were referred to as "asymptomatic individuals".

The occupations were grouped in nine categories according to the Swedish standards for occupational classification of 2018, which is adapted from the International Standards Classification of Occupations. ${ }^{13}$ The occupation groups five to nine were classified as occupations with a risk of exposure to airway irritants.

The diagnoses at inclusion and during follow-up were obtained from the AATD register questionnaires and from the SNPR. The diagnoses were coded according to the 9th and the 10th revisions of the WHO International Classification of Disease system (ICD). ${ }^{14,15}$ The ICD codes were categorized as (ICD-9; ICD-10): respiratory diseases (emphysema (492; J43), COPD (496; J44), asthma (493; J45), chronic bronchitis (490-491; J40-42)), hepatic diseases (520-579; K70-93), cardiovascular diseases (401-429; I10-52), neurological conditions (320389 , 430-438; G12.2, I60-69), cancer affecting the respiratory organs $(162 ; \mathrm{C} 34)$ and cancer affecting the female breast (174; C50.9). From the Swedish national register of 
causes of death, we extracted data on vital status and causes of death up to June 1st, 2015.

\section{Pulmonary Function Tests}

Pulmonary function tests were performed at the patients' local hospital. The European standards were requested. The results of pulmonary function tests are expressed as $\%$ of predicted values of Quanjer et al. ${ }^{16}$ Prebronchodilator values were analyzed because a reversibility test with a bronchodilator was not always consistently performed. Airflow obstruction was defined as a $\mathrm{FEV}_{1} / \mathrm{FVC}$ ratio below 0.70 . The severity of airflow obstruction was subdivided into four groups according to the guidelines of the Global Initiative of Obstructive Lung Disease (GOLD). ${ }^{17}$ The first reported $\mathrm{FEV}_{1}$ measurement at inclusion in the register was used as baseline value.

\section{Ethical Considerations}

The study was approved by the Lund University Regional Ethical Review Board (2015/186). In accordance with Swedish research regulations for register-based research, individual patient consent on being included in a study was not required. The patient data accessed complied with relevant data protection and privacy regulations.

\section{Statistical Analyses}

Baseline data were tabulated using frequencies and percentages for categorical variables. To compare categorical data, the $\chi^{2}$-test and Fisher's exact test were used. For continuous data, means with standard deviation (SD) were used when the distribution was normal, and median with range was used in a non-normal distribution. Comparisons of continuous variables with normal distribution were analyzed using the parametric tests ANOVA and post hoc Tukey, and the Kruskal-Wallis non-parametric test was used for a non-normal distribution of the data.

The follow-up time was calculated from the date of inclusion in the AATD register to the date of the first of the following occurrences: lung transplantation, death or the termination of the study on June 1st, 2016.

To investigate the annual decline in $\mathrm{FEV}_{1}\left(\Delta \mathrm{FEV}_{1}\right)$, expressed as $\mathrm{mL} \cdot \mathrm{yr}^{-1}$, the results of at least three spirometry tests, with at least two-year intervals throughout the whole follow-up time were analyzed by the same method described and reported by us in a previous study. ${ }^{4}$ Briefly, the difference between the results of the individual's last and first reported $\mathrm{FEV}_{1}$ measurement (in $\mathrm{mL}$ ) in the register was calculated, then divided by the time between the measurements (in years) and analyzed by random-effects modeling including the $\triangle \mathrm{FEV}_{1}$ as the dependent variable, age at baseline, $\mathrm{FEV}_{1}$ at baseline and the follow-up time as covariates and smoking habits, identification before the age of 14 years, occupational exposure to airway irritants and the presence of respiratory symptoms as fixed factors, and the individual patients as random-effects factors.

In order to study the risk factors for having a diagnosis of COPD we used a proportional hazards regression model, including all subjects with the diagnosis of COPD at study-end, as dichotomous dependent variable, and sex, identification before the age of 14 years, smoking habits, occupational exposure to airway irritants and respiratory symptoms as covariates.

A p-value $<0.05$ was considered statistically significant. Statistical analyses were performed with the Statistical Package for the Social Sciences (SPSS), version 27.0 (IBM Corporation, Armonk, NY, USA).

\section{Results}

During the follow-up period, 1585 individuals with severe AATD were included in the register. All individuals had phenotype PiZZ or PiZNull. No subjects with phenotype PiNullNull or other rare phenotypes with severe AATD were included in the register. Of the 1585 AAT-deficient subjects, 377 (24\%) were identified by screening and included in this study. Of these screened subjects, 240 (64\%) were identified by family screening, 109 (29\%) by neonatal screening and 28 (7\%) by any other screening (eg, screening of school children, conscripts and blood donors). The enrollment flow chart is presented in Figure 1.

The demographic data of individuals with severe AATD identified by screening at inclusion are presented in Table 1. Compared to the ever-smokers, the neversmokers were significantly younger at inclusion, had better lung function and a greater proportion of them was identified at an early age, ie before the age of 14, Table 1 . The proportion of asymptomatic subjects at inclusion was higher among the never-smokers than among the eversmokers. Of the 156 ever-smoking individuals, 72 (46\%) had stopped smoking before the AATD diagnosis, 42 (27\%) had stopped smoking after the AATD diagnosis and $42(27 \%)$ were still current smokers at inclusion in the AATD Register. Of these 42 current-smokers, 19 (45\%) stopped smoking during the follow-up. The median time between the identification of AATD and the cessation of smoking was 8.5 (range $0.03-25$ ) years. 


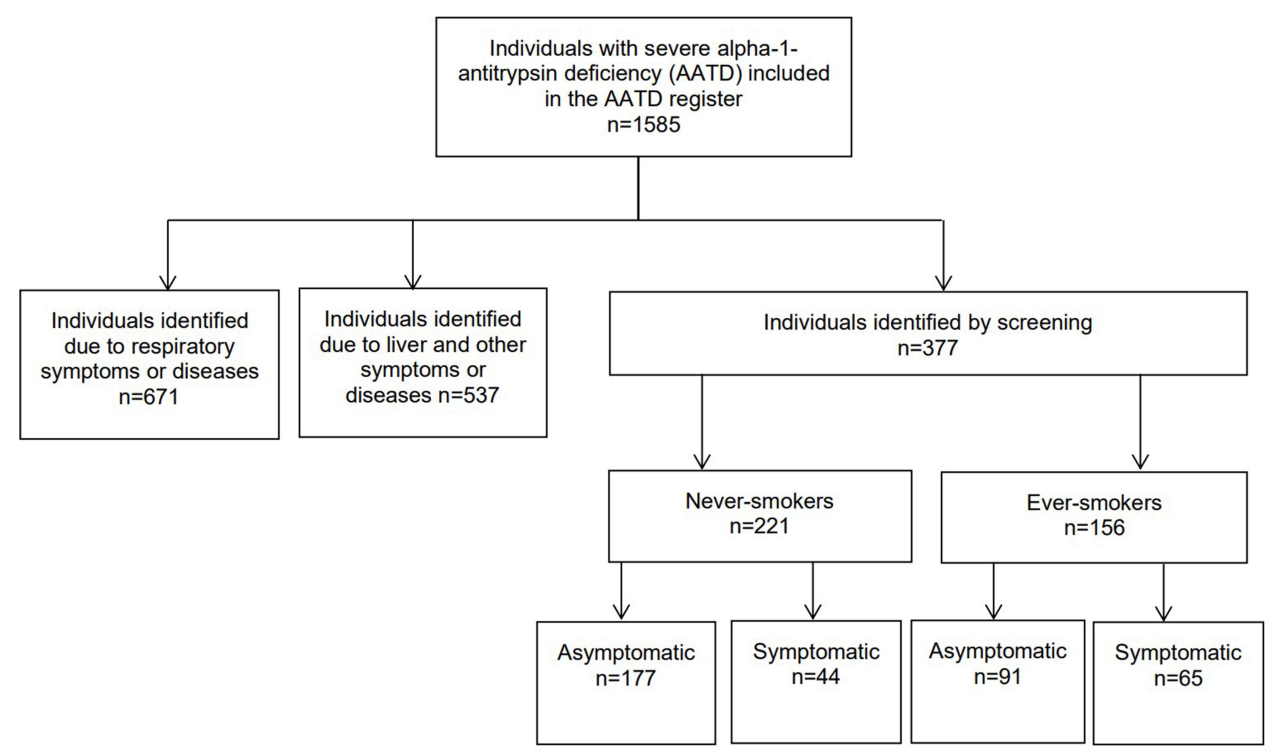

Figure I The enrollment flow chart of the individuals included in the Swedish AATD register, stratified by the mode of identification. The subjects identified by screening are subdivided by smoking habits and presence of respiratory symptoms or diagnoses at inclusion (symptomatic) or not (asymptomatic).

The diagnosis of COPD was more prevalent among the ever-smokers than among the never-smokers. The prevalence of asthma was similar among the ever- and never-smokers.

Among the subjects with respiratory symptoms without any specific diagnosis, the following symptoms were reported: dyspnea on exertion, attacks of dyspnea, phlegm, and dry cough. The mean age at onset of respiratory symptoms was 37 years (SD 14) in the ever-smokers and 48 years (SD 20) in the never-smokers. None of the individuals included in the present study received regular AAT augmentation therapy.

Occupation was known for 363 subjects (96\%). Thirtynine percent of the study population had an occupation with an increased risk of exposure to airway irritants with no significant difference between the ever- and the neversmokers, Table 1.

Baseline data for the study population stratified by smoking habits are presented in Table 2. Both among the never- and ever-smokers, the asymptomatic subjects were significantly younger at identification of AATD and inclusion in the AATD register. They also had better lung function than the symptomatic subjects at inclusion, Table 2.

At inclusion, airflow obstruction with an $\mathrm{FEV}_{1} / \mathrm{FVC}$ ratio $<0.70$ was more common among the ever-smokers than among the never-smokers, Table 1. Also, some asymptomatic subjects had airflow obstruction, Table 2 . Of the 82 subjects with airflow obstruction, 25 (31\%) had GOLD stage I, 28 (34\%) GOLD stage II, 20 (24\%) GOLD stage III and 9 (11\%) GOLD stage IV.

\section{Clinical Course During the Follow-Up Period}

During the follow-up period, 31 (12\%) of the 268 asymptomatic individuals developed COPD [ $9 \%(n=16)$ of the never-smokers and $16 \%(\mathrm{n}=15)$ of the ever-smokers; $\mathrm{p}=0.105]$, and $18(7 \%)$ individuals developed asthma $[8 \%(n=14)$ of the never-smokers and $4 \%(n=4)$ of the ever-smokers; $p=0.317]$. Five patients with COPD underwent lung transplantation during the follow-up.

\section{Decline in Lung Function}

Three or more pulmonary function tests were available for 275 individuals $(73 \%)$. The mean $\triangle \mathrm{FEV}_{1}$ for the whole study population was $47(95 \% \mathrm{CI} 42-51) \mathrm{mL} \cdot \mathrm{yr}^{-1}$. The mean $\Delta \mathrm{FEV}_{1}$ was $42(95 \% \mathrm{CI} 36-47) \mathrm{mL} \cdot \mathrm{yr}^{-1}$ in the never-smokers and $53(95 \% \mathrm{CI} 47-60) \mathrm{mL} \cdot \mathrm{yr}^{-1}$ in the ever-smokers $(\mathrm{p}=0.011)$.

Among the never-smokers, the difference in the $\triangle \mathrm{FEV}_{1}$ was insignificant between the asymptomatic and the symptomatic individuals [mean 40 (95\% CI 34-45) vs 43 (95\% CI 32-54) $\left.\mathrm{mL} \cdot \mathrm{yr}^{-1}, \mathrm{p}=0.576\right]$. Among the ever-smokers, the asymptomatic subjects had a significantly lower mean $\triangle \mathrm{FEV}_{1}$ than the symptomatic subjects [mean $39(95 \% \mathrm{CI}$ 27-50) vs $74\left(95 \%\right.$ CI 61-87) $\left.\mathrm{mL} \cdot \mathrm{yr}^{-1}, \mathrm{p}<0.001\right]$.

The mean $\triangle \mathrm{FEV}_{1}$ in the individuals with occupational exposure to airway irritants was $50(95 \% \mathrm{CI} 42-57) \mathrm{mL} \cdot \mathrm{yr}^{-1}$, compared with $51(95 \% \mathrm{CI} 44-59) \mathrm{mL} \cdot \mathrm{yr}^{-1}$ in those without such exposure $(\mathrm{p}=0.744)$. 
Table I Demographic Data for Individuals with Severe Alpha-I-Antitrypsin Deficiency Identified by Screening at Inclusion in the AATD Register

\begin{tabular}{|c|c|c|c|c|}
\hline Characteristics & $\begin{array}{l}\text { All } \\
n=377\end{array}$ & $\begin{array}{l}\text { Never-Smokers } \\
n=221\end{array}$ & $\begin{array}{l}\text { Ever- } \\
\text { Smokers } \\
n=156\end{array}$ & P-value \\
\hline Men, n (\%) & $196(52)$ & $107(48)$ & $89(57)$ & 0.098 \\
\hline Mean (range) age at identification, yrs & $24(0-77)$ & $18(0-77)$ & $32(0-67)$ & $<0.001$ \\
\hline Mean (range) age at inclusion, yrs & $36(18-78)$ & $33(18-78)$ & $40(19-70)$ & $<0.001$ \\
\hline Asymptomatic at inclusion, $\mathrm{n}(\%)$ & $268(71)$ & $177(80)$ & $91(58)$ & $<0.001$ \\
\hline Mean (range) pack-years, $\mathrm{n}$ & $9.5(0.1-48)$ & - & $9.5(0.1-48)$ & - \\
\hline Identification of AATD $\leq 14 \mathrm{yrs}, \mathrm{n}$ (\%) & $145(38)$ & $116(52)$ & $29(19)$ & $<0.001$ \\
\hline Mean (SD) FEV $(\%$ predicted) & $93(24)$ & $98(18)$ & $85(28)$ & $<0.001$ \\
\hline Mean (SD) FVC (\% predicted) & $92(16)$ & $94(14)$ & $90(19)$ & $<0.001$ \\
\hline Mean (SD) $\mathrm{FEV} / \mathrm{FVC}$ & $76(15)$ & $81(12)$ & $70(18)$ & $<0.001$ \\
\hline Subjects with $\mathrm{FEV}_{1} / \mathrm{FVC}<0.70, \mathrm{n}(\%)$ & $82(22)$ & $25(\mathrm{II})$ & $57(37)$ & $<0.001$ \\
\hline Diagnosis of COPD, $n(\%)$ & $60(16)$ & $17(8)$ & $43(28)$ & $<0.001$ \\
\hline Asthma, $n(\%)$ & $4 I(I I)$ & $22(10)$ & $19(12)$ & 0.494 \\
\hline Respiratory symptoms, n (\%) & $8(2)$ & $5(2)$ & $3(2)$ & 1.000 \\
\hline Occupational exposure, $\mathrm{n}(\%)^{\mathrm{a}}$ & $143 / 363(39)$ & $79 / 214(37)$ & $64 / 149(43)$ & 0.247 \\
\hline Median (range) follow-up time, yrs & $18(0-23)$ & $18(0-23)$ & $17(0-23)$ & 0.188 \\
\hline
\end{tabular}

Notes: ${ }^{a}$ Occupation was known in 363 subjects (96\%). Data are presented as frequency (percentage), mean (standard deviation, SD).

Abbreviations: $\mathrm{n}$, number; yrs, years; L, liter; FEV , forced expiratory volume in I second; FVC, forced vital capacity; COPD, chronic obstructive pulmonary disease.

Table 2 Baseline Data of the Study Population Stratified by Smoking Habits and Presence of Respiratory Symptoms or Disease at Inclusion

\begin{tabular}{|c|c|c|c|c|c|c|}
\hline \multirow[t]{2}{*}{ Characteristics } & \multicolumn{3}{|l|}{$\begin{array}{l}\text { Never-Smokers } \\
n=221\end{array}$} & \multicolumn{3}{|l|}{$\begin{array}{l}\text { Ever-Smokers } \\
n=156\end{array}$} \\
\hline & $\begin{array}{l}\text { Symptomatic } \\
n=44\end{array}$ & $\begin{array}{l}\text { Asymptomatic } \\
\mathrm{n}=177\end{array}$ & P-value & $\begin{array}{l}\text { Symptomatic } \\
n=65\end{array}$ & $\begin{array}{l}\text { Asymptomatic } \\
n=91\end{array}$ & P-value \\
\hline Men, n (\%) & $20(45)$ & $87(49)$ & 0.660 & $34(52)$ & $55(60)$ & 0.312 \\
\hline Mean (SD) age at identification, yrs & $32(28)$ & $15(19)$ & $<0.001$ & $38(16)$ & $28(19)$ & $<0.001$ \\
\hline Identification $\leq 14$ yrs of age, $n(\%)$ & $15(34)$ & $10 \mid(57)$ & 0.003 & $5(8)$ & $24(26)$ & 0.003 \\
\hline Mean (SD) age at inclusion, yrs & $44(20)$ & $31(12)$ & $<0.001$ & $46(12)$ & $36(13)$ & $<0.001$ \\
\hline Median (range) pack-years, $\mathrm{n}$ & - & - & - & $12(0.1-48)$ & $4(0.1-27)$ & $<0.001$ \\
\hline Mean (SD) FEV (\% predicted) & $85(22)$ & $102(15)$ & $<0.001$ & $63(28)$ & $10 \mid(13)$ & $<0.001$ \\
\hline Mean (SD) FVC (\% predicted) & $86(15)$ & $96(13)$ & $<0.001$ & $80(2 I)$ & $98(12)$ & $<0.001$ \\
\hline Mean (SD) $\mathrm{FEV}_{1} / \mathrm{FVC}$ & $0.73(0.2)$ & $0.83(0.1)$ & $<0.001$ & $0.57(0.2)$ & $0.79(0.1)$ & $<0.001$ \\
\hline Subjects with $\mathrm{FEV}_{\mathrm{I}} / \mathrm{FVC}<0.70, \mathrm{n}(\%)$ & $15(34)$ & $10(6)$ & $<0.001$ & $45(69)$ & $12(13)$ & $<0.001$ \\
\hline Median (range) follow-up, yrs & $17(0-22)$ & $19(0-23)$ & 0.099 & $15(0-23)$ & $18(I-23)$ & 0.035 \\
\hline
\end{tabular}

Note: Data are presented as frequency (percentage), mean (standard deviation, SD).

Abbreviations: $n$, number; yrs, years; $L$, liter; $\mathrm{FEV}_{1}$, forced expiratory volume in I second; FVC, forced vital capacity. 
Table 3 Characteristics of the Study Population at Inclusion Stratified by the Age at Identification (Before vs After I4 Years)

\begin{tabular}{|c|c|c|c|}
\hline Characteristics & $\begin{array}{l}\text { Identified } \leq 14 \text { Years } \\
(n=145)\end{array}$ & $\begin{array}{l}\text { Identified > } 14 \text { Years } \\
(n=232)\end{array}$ & P-value \\
\hline Men, n (\%) & $67(46)$ & $129(56)$ & 0.076 \\
\hline Mean (SD) age at inclusion, yrs & $24(4)$ & $44(14)$ & $<0.001$ \\
\hline Never smokers, n (\%) & $116(80)$ & $105(45)$ & $<0.001$ \\
\hline Asymptomatic at inclusion, $\mathrm{n}$ (\%) & $125(86)$ & $143(62)$ & $<0.001$ \\
\hline Median (range) follow-up time, yrs & $19(0-23)$ & $16(0-23)$ & $<0.001$ \\
\hline Mean (SD) FEV (\% predicted) & I0I (I4) & $87(27)$ & $<0.001$ \\
\hline Mean $\Delta \mathrm{FEV}_{\mathrm{I}}(95 \% \mathrm{Cl}) \mathrm{mL} \mathrm{yr}^{-1}$ & $33(24-42)$ & $55(49-62)$ & $<0.001$ \\
\hline Diagnosis of COPD, $n$ (\%) & $I(I)$ & $59(25)$ & $<0.001$ \\
\hline Asthma, n (\%) & $18(12)$ & $23(10)$ & 0.448 \\
\hline Occupational exposure, $\mathrm{n}(\%)^{\mathrm{a}}$ & $55 / 141$ (39) & $88 / 222(40)$ & 0.904 \\
\hline
\end{tabular}

Notes: ${ }^{a}$ Occupation was known in 363 subjects (96\%). Data are presented as frequency (percentage), mean (standard deviation, SD).

Abbreviations: $\mathrm{n}$, number; yrs, years; $\mathrm{mL}$, milliliter; $\mathrm{FEV}_{\mathrm{l}}$, forced expiratory volume in I second; COPD, chronic obstructive pulmonary disease.

\section{Subjects Identified Before the Age of 14 Years}

Thirty-eight percent $(n=145)$ of the study population had been identified at or before the age of 14 years. Compared to the individuals identified after the age of 14 years, the individuals identified before the age of 14 years had significantly better lung function and a greater proportion of them were never smokers and asymptomatic, Table 3.

\section{Risk Factors for COPD}

In the multivariate analysis, including 102 individuals with a diagnosis of COPD at study-end, the identification of AATD at an age older than 14 years and the presence of respiratory symptoms or diseases were the significant risk factors for having a diagnosis of COPD, while sex, smoking habits and occupational exposure to airway irritants were not significant, Table 4.

\section{Liver Disease and Other Diseases}

None of the individuals had any liver disease at inclusion. Fifteen (4\%) of the 337 individuals developed liver disease during the follow-up: $5 \%(\mathrm{n}=8)$ of the ever-smokers and $3 \%(n=7)$ of the never-smokers, $p=0.424$. None of them underwent liver transplantation.

At inclusion, diabetes mellitus was reported in two $(0.5 \%)$ individuals, one never smoker $(0.6 \%)$ and one ever-smoker $(0.5 \%), p=1.000$. During the follow-up diabetes mellitus was diagnosed in 9 other individuals $(2 \%)$, without any significant difference between ever- $[n=6$, $(4 \%)]$ and never-smokers $[n=5,(2 \%)], p=0.373$.

Hyperlipidemia was reported in five $(1 \%)$ individuals at inclusion [four ever-smokers $(2.6 \%)$ and one never-smoker $(0.5 \%), \mathrm{p}=0.172]$, and occurred in $12(3 \%)$ other subjects during follow up, resulting in a total number of 17 (5\%), ten ever-smokers $(6 \%)$ and seven never-smokers $(3 \%), \mathrm{p}=0.206$.

Table 4 Multivariate Analysis of Risk Factors for Having a Diagnosis of COPD (Chronic Obstructive Pulmonary Disease) at Study-End

\begin{tabular}{|l|l|l|}
\hline \multirow{2}{*}{ Variables } & COPD & P-value \\
\cline { 2 - 3 } & Hazard Ratio (95\% Cl) & 0.174 \\
\hline Women vs Men & $1.35(0.88-2.09)$ & $<0.001$ \\
\hline Age >14 years vs Age $\leq 14$ years & $9.21(2.79-30.38)$ & 0.636 \\
\hline Ever- vs Never-smokers & $1.23(0.69-1.83)$ & $<0.001$ \\
\hline Symptomatic vs asymptomatic & $4.79(2.96-7.73)$ & 0.535 \\
\hline Occupational exposure, no vs yes & $1.15(0.74-1.79)$ & \\
\hline
\end{tabular}

Abbreviations: $\mathrm{HR}$, hazard ratio; $\mathrm{Cl}$, confidence interval. 
The corresponding figures for hypertension were four $(1 \%)$ at inclusion [two ever-smokers (1\%) and two neversmokers $(1 \%), p=1.000]$, and occurred in $41(11 \%)$ other subjects, resulting in a total of $45(12 \%)$ subjects with hypertension [27 ever-smokers (17\%) and 18 neversmokers $(8 \%), p=0.009]$.

Twelve subjects (3\%) developed ischemic heart disease during the follow-up, without any significant differences between the ever- $[n=8,(5 \%)]$ and the never-smokers $[\mathrm{n}=4,(2 \%)], \mathrm{p}=0.081$. Twenty subjects $(5 \%)$ developed heart failure during the follow-up, eleven $(5 \%)$ eversmokers and nine (4\%) never-smokers, $\mathrm{p}=0.247$.

None of the individuals had any diagnosis of cancer at inclusion. One individual (0.3\%) developed urogenital cancer during follow-up.

\section{Deaths and Causes of Death}

Death occurred for 45 individuals, 32 (21\%) deaths among the ever-smokers and $13(6 \%)$ deaths among the neversmokers $(\mathrm{p}<0.001)$, Table 5 . The never-smoking individuals had significantly better survival than the ever-smoking individuals $(p<0.001)$. Since only a small number of deaths occurred, the median survival time could not be calculated. The 10-year, 15-year and 20-year survival rates were significantly higher for the never-smokers compared with the eversmokers; 0.97 (95\% CI 0.95-0.99), 0.95 (95\% CI 0.92-0.98) and 0.92 (95\% CI $0.87-0.97)$, respectively, compared with 0.89 (95\% CI 0.84-0.94), 0.82 (95\% CI 0.75-0.89) and 0.71 (95\% CI 0.62-0.80) for the ever-smokers.

The main causes of death are presented in Table 5. Cardiac causes were the most common causes of death and were present in all patient categories. None of the asymptomatic subjects died of respiratory disease. Malignancy was a cause of death only in the ever-smokers. No deaths were due to hepatocellular cancer.

\section{Discussion}

The main findings in our study are that never-smokers with severe AATD, who were identified by screening, have better lung function, a lower rate of lung function decline, and better survival compared with ever-smokers. Furthermore, the individuals diagnosed at an early age (ie $\leq 14$ years) are more often never-smokers, have better lung function, and a lower lung function decline than the subjects identified after the age of 14 years. These findings support the importance of early identification of AAT deficiency, before the assumed smoking debut, in order to improve the prognosis, by promoting early lifestyle options and preventive measures such as abstaining from smoking.

Besides the diagnosis of COPD, we found a relatively high prevalence of asthma (11\%) in these AAT-deficient individuals identified by screening. Many young and never-smoking AAT-deficient patients with airways obstruction may be misdiagnosed as having asthma rather than COPD. Previously published studies have also indicated that signs and symptoms of asthma are common in AAT-deficient individuals, and asthma is often diagnosed as the first manifestation of AATD. ${ }^{17-20}$ The neutrophil inflammation affecting the small airways and causing early asthma-like symptoms that later develop into chronic airway obstruction is another possible explanation for the high prevalence of asthma. ${ }^{17-20}$ Our results show that it is important to screen patients with asthma for AATD. Early diagnosis and treatment of asthma may also prevent the development of chronic airway obstruction. ${ }^{21}$

Thirty-nine percent of the individuals identified before the age of 14 years reported occupations with exposure to airway irritants. This finding suggests that there is a need for more information and instruction at an early age not

Table 5 Main Causes of Death in the 45 Individuals Who Had Been Identified by Screening

\begin{tabular}{|c|c|c|c|c|c|}
\hline \multirow[b]{2}{*}{ Deaths, n (\%) } & \multirow[b]{2}{*}{ All $n=45(100)$} & \multicolumn{2}{|c|}{ Never-Smokers $n=13$} & \multicolumn{2}{|c|}{ Ever-Smokers $n=32$} \\
\hline & & $\begin{array}{l}\text { Symptomatic, } \\
n=10 \text { (77) }\end{array}$ & $\begin{array}{l}\text { Asymptomatic, } \\
n=3 \text { (23) }\end{array}$ & $\begin{array}{l}\text { Symptomatic, } \\
n=23 \text { (72) }\end{array}$ & $\begin{array}{l}\text { Asymptomatic, } \\
\mathrm{n}=9 \text { (28) }\end{array}$ \\
\hline Causes of death & & & & & \\
\hline Respiratory, n (\%) & II (24) & $2(15)$ & - & $9(28)$ & - \\
\hline Hepatic, n (\%) & $3(7)$ & $2(15)$ & - & - & I (3) \\
\hline Neoplastic, n (\%) & $3(7)$ & - & - & I (3) & $2(6)$ \\
\hline Cardiac, n (\%) & $13(29)$ & $4(3 I)$ & $2(15)$ & $5(16)$ & $2(6)$ \\
\hline Cerebrovascular, n (\%) & $4(9)$ & - & I (8) & $2(6)$ & I (3) \\
\hline Other ${ }^{\mathrm{a}}, \mathrm{n}(\%)$ & II (24) & $2(15)$ & - & $6(19)$ & $3(9)$ \\
\hline
\end{tabular}

Note: "'Other" includes shock, sepsis, drowning, ill-defined and unknown cause. 
only concerning smoking but also concerning choice of occupation.

Hypertension and ischemic heart disease were more common among ever-smokers than never-smokers. Cigarette smoking is a risk factor for developing cardiovascular disease, mainly because of the adverse effects on the vascular endothelium. ${ }^{22}$ Most of these AAT-deficient individuals identified by screening were never-smokers $(59 \%)$ and a majority (85\%) of the ever-smokers had quitted smoking after the diagnosis of AAT-deficiency or after inclusion in the Register. Carpenter et al have studied the impact of knowledge of genetic status (severe AATD) on health behavior changes and found that smokers who learned that they were AAT-deficient took definite actions toward quitting smoking. ${ }^{23}$ We chose the age of 14 years as a cut-off because according to a WHO report, in Sweden, $4 \%$ of the boys and $5 \%$ of the girls aged 13 years, and $18 \%$ of the boys and $24 \%$ of the girls aged 15 years report smoking at least weekly. ${ }^{24}$ Thus, at the age of 14 years, many teenagers have already started smoking.

Since the 1970's, the question of general screening for AATD has been debated as a method of improving health status and preventing lung disease in individuals with AATD. A combination with other, routine neonatal screening for metabolic diseases would be an option. The most notable screening is the Swedish neonatal screening study, which was carried out during the 2-year period 1972-74, when all 200,000 new-born children were screened for AAT deficiency. This screening has contributed to a better knowledge of the natural history of this disorder during childhood and early adulthood. The anti-smoking advice that was given to the adolescents, was successful and has prevented the majority of them from starting to smoke. ${ }^{25,26}$ According to current guidelines, population screening of neonates, adolescents or adults is not recommended. $^{2}$ An exception may be made in countries with a high prevalence of AATD (ie, $\geq 1 / 1500$ ) and smoking and where adequate counselling services are available. ${ }^{2}$ Because for many AAT-deficient adults, the identification is made too late to prevent COPD development, it would be reasonable that the screening is recommended in early adolescence before these young adolescents may be inclined to start smoking and when they are competent enough to understand and participate in the decision to undergo screening. Holme et al have recommended screening to be done in the 20's for never smoking individuals, and the teenagers for smokers. The authors found that deviation of health status, gas transfer and computed tomography (CT) densitometry began before the age of 16 in ever-smokers and before the age of 30 in never-smokers. These findings suggest that pathological changes and the onset of clinical symptoms occur several years before the decrease in lung function parameters. ${ }^{27}$ Other studies have recommended that the genetic testing for conditions with adult-onset should be accepted only if preventive actions can be initiated before adulthood. $^{28,29}$ It is well known that in AAT-deficient individuals, lung disease is caused by smoking that is initiated often in adolescence, while the disease, COPD, develops in adulthood. Therefore, screening at an early age should decrease the risk of developing lung disease in AAT-deficient individuals.

\section{Strengths and Limitations}

Important strengths in the present study are the large study population of PiZZ individuals identified by screening, the majority of them being never-smokers and asymptomatic, ie without any respiratory symptoms at inclusion and the long follow-up time of up to 18 years. In all subjects, the Pi phenotyping was confirmed at a central, certified laboratory.

One limitation in our study was that the lung function tests were performed at different hospitals throughout Sweden, which could imply use of different spirographs and different calibration modalities. A second limitation was that we only analyzed pre-bronchodilator values of pulmonary function tests because reversibility tests were not available in all cases. A third limitation was that we used the $\mathrm{FEV}_{1} / \mathrm{FVC}$ ratio $<0.70$ as definition of airflow obstruction in stead of the lower limit of normal (LLN). The study population being relatively young at inclusion in the Register, we cannot exclude that the proportion of subjects with airflow obstruction was underestimated. A fourth limitation was that the PiZZ subjects included in the AAT deficiency register are not a random sample of PiZZ subjects in Sweden, even if the detection rate is high in Sweden $25-30 \%$ and a high proportion of individuals included in the register are identified by screening or for reasons other than respiratory disease or symptoms.

\section{Conclusions}

Never-smoking individuals with severe AATD identified by screening have better lung function, fewer symptoms and better survival compared with the ever-smokers. Diagnosing AATD at an early age, before the potential 
smoking debut, is important in order to prevent smoking and the occurrence of lung disease.

\section{Acknowledgments}

We are grateful to all the Swedish physicians who report data to the Swedish AAT-register. Hanan Tanash and Eeva Piitulainen were supported by unrestricted grants from the Swedish Heart- Lung Foundation, the Swedish Society of Medicine and the Skåne University Hospital. The authors thank Lars Jehpsson for statistical advice.

\section{Disclosure}

The authors report no conflicts of interest. The authors alone are responsible for the content and writing of the paper.

\section{References}

1. Strnad P, McElvaney NG, Lomas DA. Alpha 1 -Antitrypsin deficiency. N Engl J Med. 2020;382:1443-1455. doi:10.1056/NEJMra1910234

2. American Thoracic Society; European Respiratory Society. American Thoracic Society/ European Respiratory Society Statement: standards for the diagnosis and management of individuals with alpha-1 antitrypsin deficiency. Am J Respir Crit Care Med. 2003;168:818-900. doi: $10.1164 / \mathrm{rccm} \cdot 168.7 .818$

3. Piitulainen E, Mostafavi B, Tanash HA. Health status and lung function in the Swedish alpha 1-antitrypsin deficient cohort, identified by neonatal screening, at the age of 37-40 years. Int J Chron Obstruct Pulmon Dis. 2017;12:495-500. doi:10.2147/COPD. S120241

4. Hiller AM, Piitulainen E, Jehpsson L, Tanash H. Decline in $\mathrm{FEV}_{1}$ and hospitalized exacerbations in individuals with severe alpha-1 antitrypsin deficiency. Int $J$ Chron Obstruct Pulmon Dis. 2019;14:1075-1083. doi:10.2147/COPD.S195847

5. Sveger T. Liver disease in alpha ${ }_{1}$-antitrypsin deficiency detected by screening of 200.000 infants. $N$ Engl J Med. 1976;294:1316-1321. doi:10.1056/NEJM197606102942404

6. Piitulainen E, Tanash HA. The clinical profile of subjects included in the Swedish National Register on individuals with severe alpha 1-antitrypsin deficiency. COPD. 2015;12(Suppl 1):36-41. doi:10.3109/15412555.2015.1021909

7. Larsson C. Natural history and life expectancy in severe alpha ${ }_{1--}$ antitrypsin deficiency, PiZ. Acta Med Scand. 1978;204:345-351. doi:10.1111/j.0954-6820.1978.tb08452.x

8. Seersholm N, Kok-Jensen A, Dirksen A. Survival of patients with severe $\alpha_{1}$-antitrypsin deficiency with special reference to non-index cases. Thorax. 1994;49:695-698. doi:10.1136/thx.49.7.695

9. Stoller JK, Tomashefski J Jr, Crystal RG, et al. Mortality in individuals with severe deficiency of $\alpha_{1}$-antitrypsin: findings from the National Heart, Lung and Blood Institute Registry. Chest. 2005;127:1196-1204. doi:10.1378/chest.127.4.1196

10. Tanash HA, Nilsson PM, Nilsson JA, Piitulainen E. Clinical course and prognosis of never-smokers with severe alpha-1-antitrypsin deficiency (PiZZ). Thorax. 2008;63:1091-1095. doi:10.1136/thx.200 8.095497

11. Tanash HA, Ekström M, Rönmark E, Lindberg A, Piitulainen E. Survival in individuals with severe alpha 1-antitrypsin deficiency (PiZZ) in comparison to a general population with known smoking habits. Eur Respir J. 2017;50:1700198. doi:10.1183/139930 03.00198-2017
12. Ludvigsson JF, Andersson E, Ekbom A, et al. External review and validation of the Swedish national inpatient register. BMC Public Health. 2011;11:450. doi:10.1186/1471-2458-11-450

13. SBC. Standard för svensk yrkesklassificering - arbetsmarknad. Hjälpmedel för kodning av yrke eller befattning 2018, enligt SSYK. [Statistics Sweden. The Swedish standards for occupational classification]. Swedish. Available from: https://www.scb.se/contentassets/ 9f203b733c2942ec971fb098a7800417/ssyk-2019.pdf. Accessed June 9, 2020.

14. World Health Organization \& International Conference for the Ninth Revision of the International Classification of Diseases (1975: Geneva). Manual of the international statistical classification of diseases, injuries, and causes of death: based on the recommendations of the ninth revision conference, 1975, and adopted by the Twenty-ninth World Health Assembly, 1975 revision. Vol. 1. Geneva: World Health Organization; 1977. Available from: http://apps.who.int/iris/handle/ 10665/40492. Accessed March 20, 2020.

15. World Health Organization. International Statistical Classification of Diseases and Related Health Problems. 10th Revision. Vol. 1. Geneva: World Health Organization; 1992.

16. Quanjer PH, Tammeling GJ, Cotes JE, et al. Lung volumes and forced ventilatory flows. Report working party standardization of lung function tests, European Community for Steel and Coal. Official Statement of the European Respiratory Society. Eur Respir J Suppl. 1993;6(Suppl 16):5-40. doi:10.1183/09041950.005s1693

17. Global Initiative for Chronic Obstructive Lung Disease [www.gold copd.com]. Global strategy for the diagnosis, management, and prevention of chronic obstructive pulmonary disease, 2020 report. Available from: https://goldcopd.org/wp-content/uploads/2019/12/GOLD-2020FINAL-ver1.2-03Dec19 WMV.pdf. Accessed March 20, 2020.

18. Eden E, Strange C, Holladay B, Xie L. Asthma and allergy in alpha-1 antitrypsin deficiency. Respir Med. 2006;100:1384-1391. doi:10.1016/j.rmed.2005.11.017

19. DeMeo DL, Sandhaus RA, Barker AF, et al. Determinants of airflow obstruction in severe alpha1-antitrypsin deficiency. Thorax. 2007;62:806-813. doi:10.1136/thx.2006.075846

20. Barker A, Brantly M, Campbell E, Carrell R, Cox, DW, Dirksen, AE. Alpha-1Antitrypsin deficiency: memorandum from a WHO meeting. Bull World Health Organ. 1997;75:397-415.

21. McGeachie MJ. Childhood asthma is a risk factor for the development of chronic obstructive pulmonary disease. Curr Opin Allergy Clin Immunol. 2017;17:104-109. doi:10.1097/ACI.0000000000000348

22. Barua RS, Ambrose JA, Eales-Reynolds LJ, DeVoe MC, Zervas JG, Saha DC. Heavy and light cigarette smokers have similar dysfunction of endothelial vasoregulatory activity: an in vivo and in vitro correlation. J Am Coll Cardiol. 2002;39:1758-1763. doi:10.1016/ S0735-1097(02)01859-4

23. Carpenter MJ, Strange C, Jones Y, et al. Does genetic testing result in behavioral health change? Changes in smoking behavior following testing for alpha-1 antitrypsin deficiency. Ann Behav Med. 2007;33:22-28. doi:10.1207/s15324796abm3301 3

24. WHO Regional Office for Europe. Health and health behaviour among young people. WHO policy for children and adolescents; Copenhagen; 2000.

25. Thelin T, Sveger T, McNeil TF. Primary prevention in a high-risk group: smoking habits in adolescents with homozygous alpha-1-antitrypsin deficiency (ATD). Acta Paediatr. 1996;85:1207-1212. doi:10.1111/j.1651-2227.1996.tb18230.x

26. Sveger T, Thelin T, McNeil TF. Young adults with alpha 1-antitrypsin deficiency identified neonatally: their health, knowledge about and adaptation to the high-risk condition. Acta Paediatr. 1997;86:37-40. doi:10.1111/j.1651-2227.1997.tb08828.x

27. Holme J, Stockley JA, Stockley RA. Age related development of respiratory abnormalities in non-index $\alpha-1$ antitrypsin deficient studies. Respir Med. 2013;107:387-393. doi:10.1016/j.rmed.201 2.12 .003 
28. Borry P, Evers-Kiebooms G, Cornel MC, Clarke A, Dierickx K; Public and Professional Policy Committee (PPPC) of the European Society of Human Genetics (ESHG). Genetic testing in asymptomatic minors: background considerations towards ESHG Recommendations. Eur J Hum Genet. 2009;17:711-719. doi:10.1038/ejhg.2009.25
29. European Society of Human Genetics. Genetic testing in asymptomatic minors: recommendations of the European Society of Human Genetics. Eur J Hum Genet. 2009;17:720-721. doi:10.1038/ejhg.20 09.26

\section{Publish your work in this journal}

The International Journal of COPD is an international, peer-reviewed journal of therapeutics and pharmacology focusing on concise rapid reporting of clinical studies and reviews in COPD. Special focus is given to the pathophysiological processes underlying the disease, intervention programs, patient focused education, and self management

Submit your manuscript here: https://www.dovepress.com/international-journal-of-chronic-obstructive-pulmonary-disease-journal protocols. This journal is indexed on PubMed Central, MedLine and CAS. The manuscript management system is completely online and includes a very quick and fair peer-review system, which is all easy to use. Visit http://www.dovepress.com/testimonials.php to read real quotes from published authors. 